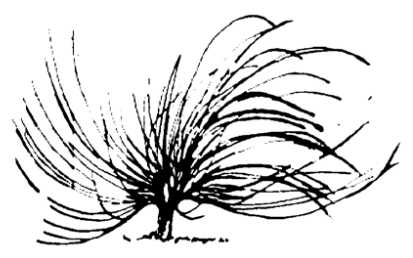

\title{
A escrita de diário de campo e a formação do professor de português
}

\author{
Emari Andrade \\ Universidade de São Paulo \\ Brasil \\ emaryjesus@yahoo.com.br
}

\begin{abstract}
Resumo
Este trabalho toma como objeto de estudo o modo como alunos de graduação em Letras de Universidades brasileiras registram a realidade escolar que observam e a maneira como se implicam (ou não) com a qualidade do registro e com essa realidade. $\mathrm{O}$ artigo analisa diários de campo de graduandos de três universidades públicas brasileiras localizadas na Bahia, Mato Grosso e São Paulo, no período de 2009 a 2014. O trabalho busca, com esse esforço, refletir a respeito da importância de tomar como objeto de análise aquilo que o próprio professor em formação escreve, na direção de ajudá-lo a construir um lugar enunciativo desde o qual pense a respeito do ensino e possa se assenhorar da profissão docente. A análise dos dados permitiu mostrar que nos registros dos futuros professores são encontrados, por um lado, impasses que indicam uma posição enunciativa mais passiva e, por outro, indícios de uma posição mais ativa e curiosa frente à sala de aula.
\end{abstract}

Palavras-chave: Escrita, diário de campo, formação de professores.

1 Professora do Departamento de Metodologia do Ensino e Educação Comparada da Faculdade de Educação de Universidade de São Paulo. 


\begin{abstract}
This article focuses on the study of how Language and Literature undergraduate students from Brazilian universities register what they observe in schools and the way they involve themselves (or not) with the quality of the register and the reality examined. It analyses undergraduate students' field diaries produced in three Brazilian public universities located in Bahia, Mato Grosso, and São Paulo, from 2009 to 2014. It aims, therefore, to reflect upon the importance of taking as a subject of analysis that which the training teacher him/ herself writes in field journals, as a means of helping him/ her construct an enunciative place from which it becomes possible to think about education and master the teaching profession. The data analysis allowed us to show that, in the registers of future teachers, there are, on the one hand, impasses that indicate a more passive enunciative position and, on the other hand, signs of a more active and curious position concerning the classroom.
\end{abstract}

Keywords: writing, field diary, teacher training

\title{
Introdução
}

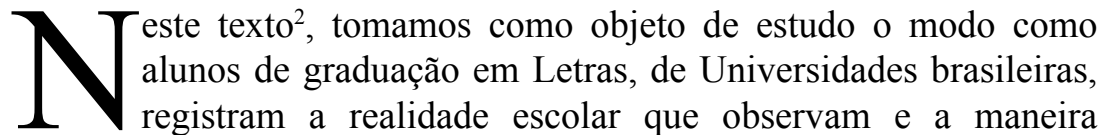
como se implicam com a qualidade do registro e com essa realidade. Entendemos que uma formação universitária que visa à docência, dependendo do modo como for conduzida e vivenciada, pode levar quem dela se beneficia a sofrer uma transformação no modo como se relaciona com sua palavra, com o saber e, consequentemente, com a carreira docente que, no caso do professor de português, toma como objeto de ensino o trabalho com a linguagem.

2 Este trabalho é resultado de nossa participação no projeto A escrita sobre as práticas de ensino em licenciaturas do Brasil, de Costa Rica e de Honduras: registro, análise e produção de conhecimento, feita em cooperação com universidades de três países (Chamada Universal MCTI/ CNPQ No 14/2014, sob coordenação do Prof. Dr. Thomas Massao Fairchild, da Universidade Federal do Pará). A pesquisa, financiada pelo CNPq, tem como objetivo discutir o papel da escrita nas licenciaturas, considerando que escrever sobre as práticas, para o professor em formação, não consiste apenas em uma forma de documentar ou comprovar suas atividades, mas é um trabalho do qual pode resultar a produção de conhecimento (Fairchild, 2008). 
Essa transformação, no entanto, não ocorre de maneira automática. Ela exige um trabalho ativo de observação, elaboração, curiosidade intelectual e pedagógica que desestabilize os significantes sobre os quais o aluno - professor em formação - se ancorava, seja em relação à escola, ao ensino da disciplina que vai lecionar ou à própria carreira docente. Nesse sentido, concordamos com Riolfi $(2003,2007)$ e Fairchild (2008, 2009) que defendem a escrita com um poderoso "dispositivo pedagógico", justamente porque exige esse trabalho reflexivo com a linguagem.

Os autores trabalham em uma linha a partir da qual postulam que, em qualquer área do conhecimento, a escrita é um elemento central na formação universitária, porque permite, àquele que está em formação, fazer um trabalho específico de retroação sobre seu próprio escrito e, sendo sensível aos efeitos de linguagem sobre o corpo, pode, ao trabalhar sobre seu escrito, descobrir algo a respeito de si que causa transformação subjetiva.

No caso específico dos registros que o aluno da licenciatura em Letras faz das práticas didáticas que observa, entendemos que ao construir linguisticamente um texto que descreva sua experiência como estagiário em sala de aula e relacioná-la com os conhecimentos adquiridos ao longo do curso, o professor em formação marca uma forma de se inscrever como sujeito. Tal forma pode ser lida pelo docente responsável pelas disciplinas relacionadas à formação do professor de português e ser tomada como objeto de reflexão em sala, na direção de construir conhecimento docente.

Tendo em vista as distintas realidades escolares, entendemos que é essencial que o graduando em letras se responsabilize por seu estágio e assuma sempre uma posição de pesquisador diante dos fenômenos da linguagem com os quais se depara, como apontado por Zabalza (2004). Isso quer dizer que os ambientes de estágio ou a realidade escolar não estão dados, mas fazem parte de um processo com base em um movimento de perguntas e de reflexão sobre o que se escolhe fazer e sobre como se pode transformar a atuação, considerando o contexto em que se atua. Empiricamente, há uma escola, uma sala de aula, um professor. No entanto, a realidade escolar se constrói não pelo local geográfico, mas pelas relações de ensino que se constroem nesses espaços. Nessa perspectiva, o fato de o aluno estagiário estar inserido nesse lugar não 
o faz um pesquisador implicado com o ensino. Trata-se de uma posição subjetiva a ser construída ao longo de sua formação.

Interessados, então, em saber os modos como o aluno de graduação em Letras registra a realidade escolar que observa e a maneira como se implica com a qualidade do registro e com essa realidade, fomos analisar diários de campo de graduandos em Letras de três universidades públicas, localizadas nos estados brasileiros da Bahia, Mato Grosso e São Paulo, no período de 2009 a 2014. Buscamos, com nosso esforço, refletir a respeito da importância de tomar como objeto de análise aquilo que o próprio professor em formação escreve, na direção de ajudá-lo a construir um lugar enunciativo desde o qual reflita a respeito do ensino e possa se assenhorar da profissão docente.

\section{A intrínseca relação entre escrita, pesquisa e formação de professores}

Consideramos a existência de uma relação intrínseca entre escrita, pesquisa e a formação do professor, em especial daqueles que escolheram como lócus de sua atuação a área das ciências da linguagem. Assim, compartilhamos uma concepção de escrita, tal como sustentada por Riolfi e Barzotto (2011, p. 09), vinculada "à sua compreensão como registro de marcas do sujeito pelo depósito no papel de conhecimento ou de dados produzidos ou em produção; como trabalho com, da e sobre a escrita". Nessa perspectiva, defendemos que é por meio do trabalho de pesquisa e da lida com os recursos linguístico-textuais que o sujeito se forma como pesquisador e como professor.

Assim, a escrita não é entendida como uma tarefa mecânica, mas como a possibilidade de o aluno-pesquisador constituir a si mesmo como professor e pesquisador da linguagem. Partimos da premissa de que a formação do professor, seja de qualquer nível, precisa passar pelo exercício de embate com a escrita.

Inspiramo-nos na postulação de Riolfi (2007), que justifica o destaque dado à escrita, no contexto de formação de professores, devido ao fato de que, dada a natureza do trabalho com a linguagem que a escrita exige, trata-se de um campo privilegiado que permite a reflexão a respeito da realidade escolar vivenciada, do trabalho com a linguagem, bem como da própria postura do aluno em formação frente a essa realidade.

Diferente das outras operações que se podem realizar com a linguagem - por exemplo, o falar - a escrita requer um trabalho intenso 
por parte de quem decide compartilhar uma experiência por meio dela. Exige uma ordenação do pensamento, depuração das ideias, escolha da palavra para uma dada descrição, a retroação sobre o texto para calcular os possíveis efeitos de sentido dele, enfim, uma série de operações com a linguagem que permitem ao futuro professor dar a ver até mesmo aquilo que, sem a lida com a escrita, nunca se daria conta de que sabia.

Assim, nossa compreensão é que o fato de o aluno-pesquisador entrar em uma sala de aula, tomá-la como locus de pesquisa, observá-la e escrever a respeito do que observou, de como os alunos leem, falam, escrevem, analisam a língua, pode causar efeitos naquele que está sendo formado. Desse modo, a partir de um movimento de retroação, o aluno-pesquisador pode exercitar um olhar diferenciado acerca de uma vivência da escola e, ao fazer isso, pode mudar sua relação com sua palavra e com aquilo que está elaborando.

A construção de um lugar como aluno-pesquisador não é, portanto, dada a priori. Trata-se de uma conquista a cada nova experiência de estágio, a cada nova pesquisa que se dispõe a fazer. Por essa razão, entendemos que apesar de a instituição escolar, com todos os seus símbolos, deveres, regras, especificidades, não ser um lugar desconhecido para o aluno-pesquisador, tampouco a função de professor, o lugar de aluno-pesquisador é algo a ser conquistado subjetivamente.

A partir de um referencial teórico da psicanálise, entendemos que o sujeito é constituído na e pela linguagem, tal como entendido por Jacques Lacan (1964). Assim, ao caminharmos na inclusão de um além de um sujeito da cognição, aquele que adquire conhecimento por meio da compreensão, do raciocínio lógico, consideramos que quem escreve: a) pode assumir diferentes posições frente ao saber; b) pode sofrer transformações subjetivas decorrentes do tipo de laço social em que se insere, as quais podem ser localizadas no texto.

Por essa razão, insistimos na necessidade de, ao longo da formação de professores, pensar em modos de ensinar o aluno da graduação a bem-escrever. Isso porque a escrita não é um processo que se define por sua materialidade, mas, ao contrário, consiste em práxis que pode trazer transformação subjetiva.

Nesse sentido, perguntamos: o que seria uma experiência de formação, de estágio e de escrita que resulte em uma transformação naquele que por ela passa? Para refletir a esse respeito, trazemos a discussão elaborada por Jorge Larrosa (2004), autor que propõe que se 
pense a educação a partir do par experiência/sentido. Explorando a definição da palavra experiência em várias línguas, o autor a define como "algo que nos passa, o que nos acontece, o que nos toca" e chama a atenção para uma realidade do nosso mundo: "nunca se passaram tantas coisas, mas a experiência é cada vez mais rara" (p. 116).

Ao entender o período de realização das disciplinas de estágio em língua portuguesa como um espaço de formação que pode resultar em uma experiência, na acepção adotada por Larrosa (2004), recuperamos aqui, brevemente, as razões pelas quais o autor afirma ser a experiência algo raro de acontecer nos dias de hoje. Podemos ler o texto do filósofo entendendo que as razões ali colocadas são empecilhos para a relação que o aluno estabelece com as instâncias de ensino-aprendizagem, tais como a escola, a pesquisa e a escrita. São elas:

- $\quad$ excesso de informações: pela preocupação extrema em obter o maior número de informações possíveis em tempo recorde, a pessoa cancela a possibilidade de experiência, já que não se deixa ser permeável às informações que recebe, ou seja, não consegue transformar a quantidade de informações sobre um assunto em conhecimento. $\mathrm{O}$ autor é categórico nesse ponto: "a informação não é experiência" (p. 116);

- O excesso de opinião: além de ser informado, o homem moderno é alguém que tem uma opinião supostamente pessoal, própria e crítica a respeito de tudo o que lhe chega como informação. Na visão do autor, opinar a respeito de tudo virou um imperativo na sociedade atual, de modo que aquele que não emite uma opinião própria acerca do assunto do momento sente-se falso, com se lhe faltasse algo essencial. Regida pela obsessão de ter uma opinião sobre tudo, a pessoa não se permite que o saber da experiência aconteça, isso porque a opinião pessoal sempre está calcada no senso comum;

- A falta de tempo: tudo acontece muito rapidamente, queremos saber algo novo com uma velocidade intensa, de modo que essa velocidade impede a memória e a conexão significativa entre os acontecimentos. "Ao sujeito do estímulo, da vivência pontual, tudo o atravessa, tudo o excita tudo o agita, tudo o choca, mas nada lhe acontece" (p. 120); 
- $O$ excesso de trabalho: o homem moderno tem a pretensão de conformar o mundo segundo seu saber, sua vontade. Ele acredita que pode fazer tudo o que se propõe e, para isso, não hesita em destruir tudo o que se apresenta como obstáculo à sua onipotência. Ele nunca pode parar e, por isso, não dá lugar para que a experiência aconteça. $\mathrm{O}$ autor ressalta que não se pode confundir experiência com trabalho; aliás, ele coloca que o trabalho é inimigo da experiência.

É interessante observar que as razões discutidas por Larrosa (2004) configuram-se como armadilhas nas quais a pessoa pode cair e, assim, não alcançar o saber da experiência, aquele que "se dá na relação entre o conhecimento e a vida humana" (p. 128). Podemos afirmar, portanto, a partir das considerações do autor que, no campo da formação de professores, um estágio ou uma disciplina que não se configura como uma experiência passa na vida do aluno sem causar transformação, cumprindo, apenas, um caráter burocrático; passa sem que o graduando construa e se ancore em um lugar subjetivo desde onde planeje suas atividades em sala de aula, escreva a partir de suas observações e projete seu futuro profissional. Trata-se de um "não lugar", no qual, mesmo que a pessoa esteja geograficamente em um ambiente educativo, não consegue ser permeável aos efeitos transformadores que a relação do ser humano com o conhecimento pode propiciar.

É justamente por defender que a graduação, em especial o período de estágio, pode ser um ambiente educativo transformador para a vida daquele que está sendo formado, que ressaltamos a importância de se desenvolverem práticas de escrita e de pesquisa que resultem em produção de conhecimento por parte dos estudantes.

Entendemos que o período do estágio é fulcral na carreira do professor em formação. Trata-se do momento em que ele tem seu trabalho institucionalmente acompanhado e orientado por um professor mais experiente. Por essa razão, pode apresentar-se como um processo relevante não apenas pela sua propriedade formativa intrínseca ao curso de habilitação profissional para o magistério, mas também pela possibilidade que se abre ao aluno-pesquisador de apreensão e compreensão da prática vivenciada à luz de conhecimentos específicos, os quais podem agir como instrumentais de reflexão, indagação e de produção de conhecimentos sobre a prática. 
Partimos, portanto, de uma concepção de estágio que é construído e integrante na formação do professor a partir da observação e reflexão feitas por meio da escrita. A nosso ver, ensinar o aluno de graduação a analisar os efeitos de sentido de seu texto é essencial para que ele retroaja sobre seu próprio escrito e sobre a visão que, inicialmente, tem a respeito do seu papel enquanto pesquisador da linguagem e futuro professor de língua portuguesa.

Sabemos que muito se tem discutido a respeito da formação inicial de estudantes de licenciaturas e da importância de se superar o abismo entre teoria e prática. Afirmações de que teoria e prática são bastante dissociadas, de que a realidade não permite a aplicação do conteúdo aprendido, de que existe uma grande distância entre os conhecimentos adquiridos durante os cursos de licenciatura e o que o graduando encontra na prática são afirmações cada vez mais comuns. Essa oposição, frequentemente explicitada por alunos e professores, revela também o desejo de buscar novas formas de relacionamento entre estas duas dimensões da realidade. Trata-se de uma das questões básicas da formação do professor e constitui o ponto central de reflexão na busca de alternativas para a formação desses profissionais.

Pimenta e Lima (2005) afirmam que no movimento teórico recente a respeito da concepção de estágio é possível situar duas perspectivas que marcam a busca para superar a dicotomia entre atividade teórica e atividade prática: a primeira é o estágio como aproximação da realidade e atividade teórica e a segunda é o estágio como prática de pesquisa.

$\mathrm{Na}$ primeira, as autoras consideram que a finalidade do estágio é propiciar ao aluno uma aproximação da realidade na qual atuará. Assim, o estágio se afasta da compreensão até então corrente de que seria a prática do curso. As autoras defendem uma nova postura, uma redefinição do estágio que deve caminhar para a reflexão a partir da realidade e introduzem a discussão de práxis na tentativa de superar a dicotomia. $\mathrm{Na}$ segunda, a pesquisa no estágio se traduz, por um lado, em pesquisas que permitam a ampliação e análise dos contextos nos quais o estágio se realiza e, por outro, na possibilidade de os estagiários desenvolverem posturas de pesquisador, elaborando projetos de intervenção para a realidade observada e tendo a possibilidade de construir um lugar enunciativo desde o qual pautará suas ações.

Nessa perspectiva, acredita-se que o estágio é essencial não apenas pela sua propriedade formativa intrínseca ao curso de habilitação 
profissional para o magistério, mas também pela possibilidade que se abre ao aluno-estagiário de apreensão/compreensão da prática vivenciada à luz dos conhecimentos específicos de sua área de atuação. Enfim, é o elemento essencial para que o professor construa sua identidade docente. Nas palavras de Pimenta:

Uma identidade profissional se constrói, pois, a partir da significação social da profissão, da revisão constante dos significados sociais da profissão, da revisão das tradições. Mas também da reafirmação de práticas consagradas culturalmente e que permanecem significativas. Práticas que resistem às inovações porque prenhes de saberes válidos às necessidades da realidade. Do confronto entre as teorias e as práticas, da análise sistemática das práticas à luz das teorias existentes, da construção de novas teorias. Constrói-se, também, pelo significado que cada professor, enquanto autor, confere à atividade docente em seu cotidiano a partir de seus valores, de seu modo de situar-se no mundo, de sua história de vida, de suas representações, de seus saberes, de suas angústias e anseios, do sentido que tem em sua vida o ser professor. Assim como a partir de sua rede de relações com outros professores, nas escolas, nos sindicatos e em outros agrupamentos. (PIMENTA, 2004, p. 99)

Tendo como referência outros estudos que tomaram como objeto textos produzidos por alunos da licenciatura em letras (Barzotto e Eufrásio, 2009; Eufrásio, 2007; Fairchild, 2008; 2009, Barzotto e Puh, 2015), um dos principais desafios é o professor em formação descontruir uma visão ora muito preconceituosa com relação às práticas observadas em sala de aula, ora muito deslumbradas.

Fairchild (2008), por exemplo, analisou quatro problemas que encontrou em relatórios de estágio de graduandos em letras: 1) Descrições insuficientes do que ocorre em sala de aula - escritas que indicam o conteúdo que foi feito na aula, mas não descrevem o transcurso do que ocorreu; 2) descrições que indicam o mau tempo do estágio - escritas que não indicam ou não demonstram a presença do estagiário em sala de aula; 3) descrições que relatam, preferencialmente, aspectos da escola já assinalados em um discurso anterior à experiência do aluno, ou seja, uma escrita calcada em um senso comum a respeito da escola e 
não considerando a formação do estagiário; e 4) conclusões ou análises não relacionadas com a experiência e os dados recolhidos pelo aluno.

$\mathrm{Na}$ sequência, analisaremos outros dois problemas comuns que encontramos em textos de graduandos em letras. Os dados fazem parte do corpus do projeto coletivo, sendo coletados por professores das disciplinas de metodologia do ensino da língua portuguesa ou estágio supervisionado. Ambas as disciplinas tinham como um dos instrumentos de avaliação a escrita de um diário de campo, que registrasse as 60 horas de estágio do aluno, em cada semestre.

\section{O deslumbramento que soterra o professor em formação}

Apresentaremos um excerto retirado de um diário de campo produzido por uma aluna que, à época, cursava o sétimo semestre do curso de letras de uma Universidade Estadual na Bahia, região Nordeste do Brasil. Trata-se de uma das primeiras aulas observadas pela aluna, isso porque devido a uma greve na Universidade, o semestre letivo tinha começado no final de outubro. Apesar de estar no último ano do curso de Letras, era a primeira vez que a graduanda tinha contato mais próximo com uma sala de aula. Até então, as experiências pedagógicas tinham sido feitas em Oficinas de Língua Portuguesa ministradas aos próprios colegas de turma, dentro da Universidade. Leiamos o trecho:

01 No dia quatro de novembro, observei essas aulas surpreendentes.

Confesso que

por se tratar de um colégio público, minhas expectativas não eram as melhores

03 possíveis, mas elas foram superadas a partir do momento em que a professora

04 me recebeu. Estava estampado o seu gosto pela profissão num mero "Boa tarde, meus amores"... E aí, tudo em cima?!", docemente embalado por ela, em alto e bom som. A aula começa de uma maneira maravilhosa, um papo legal para descontrair, e depois correção de um exercício muito extenso, de um

08 assunto nada interessante: sintagma nominal e verbal.

09 O texto motivador do exercício era a música "Vamos fugir" de Skank, que antes de mais 
nada, foi cantada por todos, depois de muita insistência. Ao decorrer da correção, é

11

percebido que a maioria dos alunos não fez a atividade proposta, já que se trata de final

12

de ano e metade da turma já está passada e outra metade praticamente perdida.

[...] A metodologia da professora é indiscutível. Cutucando um dali e outro de cá, com

14

brincadeirinhas (no momento certo, é claro) e incentivos, ela vai prendendo a atenção

15

de todos, o que é difícil, quando se tem uma turma de $1^{\circ}$ ano. [...] Essa metodologia faz

com que o aluno se sinta ambientado para tirar suas dúvidas, e com certeza, por esse

17 motivo, consegue aprender de uma maneira mais "confortável", digamos.

Dentre os aspectos que poderíamos discutir desse trecho, destacamos o modo como a estagiária não se inclui no processo de alguém que pesquisa a linguagem e os processos de ensino. A graduanda em letras escreve desde um ponto de vista "encantado" com a prática da professora que está observando. Ao escrever, é do lugar do senso comum e dos seus preconceitos que escreve as primeiras 8 linhas do relato. Lembremos que, para Pécora (1992), o senso comum são segmentos congelados da linguagem que representam a diluição de sua especificidade.

No caso desse excerto, a estagiária, já nas duas primeiras linhas, escreve que suas expectativas "não eram as melhores possíveis" e dá ao relato um tom confessional. Já na primeira linha, a aluna utiliza o verbo "confessar" para apresentar seu ponto de vista a partir da aula observada. Naquele momento, é desde a posição de alguém que está fixada em seus preconceitos e expectativas que passa a descrever a aula a que assiste, a ponto de maravilhar-se com o que encontra. As escolhas lexicais para valorar a aula e atitude da professora são: "indiscutível", "maravilhosa", "surpreendente", "papo legal", "docemente embalado". No entanto, todos esses atributos são feitos de maneira vaga, sem recolher elementos que justificassem o seu ponto de vista. Trata-se de relato 
feito a partir da opinião da estagiária, que não mobiliza os conhecimentos por ela aprendidos ao longo da graduação.

Entre as linhas 7 e 8, a estagiária comenta que foi feita a correção de um exercício extenso (como calcular essa extensão?) "nada interessante": sintagma nominal e verbal. Como o exercício não é copiado no diário nem colocado como anexo, o leitor precisa imaginar o que seria um exercício extenso e nada interessante para aquela turma. O leitor então não consegue calcular o modo como a estagiária avaliou o resultado do exercício e sua extensão, já que tais critérios não são colocados em nenhuma outra parte do diário.

Interessante notar, ainda, que nas primeiras linhas a estagiária começa o relato escrevendo na primeira pessoa do singular, mas a partir da linha nove até o final escreve na terceira pessoa do singular, valendo-se das formas impessoais dos verbos. Apesar de citar que o texto motivador para o exercício era a música "Vamos fugir", de um grupo de pop rock brasileiro, não descreve o exercício e o modo como o texto foi usado como pretexto para uma atividade metalinguística da língua. Não sabemos, também, por que a professora precisou insistir tanto para que os alunos cantassem a música. Era necessário? Em nenhum momento a estagiária apresenta um olhar mais curioso a respeito daquela aula.

A nosso ver, é como se a estagiária tivesse sido soterrada com o deslumbramento de estar em uma sala de aula e, já que suas expectativas eram tão ruins acerca do ensino público, precisou ir sempre positivando a aula a que assistia. Nesse ponto, ela não se questiona em nenhum momento, mas dá crédito às justificativas de que os alunos não fizeram a atividade porque "metade da sala está passada e outra metade praticamente perdida" (linha 12). Como era a primeira vez que estava nessa turma, muito provavelmente a estagiária soube dessa informação pela professora. Sem questionar-se, por exemplo, o que é uma turma "passada" ou "perdida", ela toma a palavra da professora como sua e a divulga.

Entre as linhas 13 e 15, a estagiária afirma que a metodologia da professora é indiscutível. Nesse ponto, assume uma posição de avaliadora da aula, não de pesquisadora. Segundo ela, a metodologia é "indiscutível", porque a professora consegue "prender a atenção de todos". Nesse aspecto, poderíamos questionar a respeito do que a estagiária pensa ser a função do professor de português. Chamar a atenção para si ou para a produção dos alunos, para as práticas de reflexão sobre 
a língua? Por que uma classe de primeiro ano do ensino médio traz mais desafios ao professor? O que a aluna nomeia como "metodologia"?

Enfim, são perguntas que o professor supervisor de estágio ou da disciplina de metodologia poderia fazer longo das aulas, buscando levar a estagiária a esvaziar o texto desse discurso do senso comum e das descrições gerais a respeito da aula, auxiliando-a a ter um olhar mais analítico a respeito da realidade por ela observada. Outro aspecto importante seria trabalhar com a identificação irrefletida com o professor regente da turma. É preciso que o estagiário encontre o seu lugar dentro da sala de aula para que não caia em dois extremos: a crítica inócua ao trabalho do professor ou a identificação total. Preso tanto a uma posição quanto a outra, o estagiário deixa de ser curioso e de responsabilizar-se por seu papel dentro da escola.

\section{Não assunção da responsabilidade como estagiário}

O próximo trecho a ser analisado foi retirado de um diário de campo de uma aluna do sétimo semestre do curso de Letras de uma Universidade Estadual do Mato Grosso, Centro-Oeste do Brasil. Se no primeiro exemplo vimos uma aluna deslumbrada com o seu primeiro contato na escola, quisemos, neste momento, escolher um relato de uma aluna no final do seu período de estágio. Trata-se do momento em que ela descreve e analisa a regência feita em uma turma de oitavo ano do ensino fundamental.

01

Assim terminamos a nossa regência convictos de que a docência é provida de altos e

02

baixos, que temos muito a aprender no espaço da sala de aula. Tenho em mente que

apesar de sermos leigos [grifo nosso], conseguimos atingir nosso objetivo, apresentar

[ uma proposta

que contribui-se com uma aprendizagem fora do contexto do dia-a-dia desses alunos,

05 fugir um pouco de conteúdos propostos pelo livro didático.

Para além de uma conclusão calcada não na experiência como estagiária, mas em um senso comum de que "a docência é provida de altos e baixos" (linhas 1 e 2), o relato da aluna não apresenta indícios 
efetivos de que a graduanda fez a regência. Ou seja, não há nada de específico que indicie a presença da aluna na escola. Não apresenta, por exemplo, que tipo de proposta foi feita, em que foi baseada, quais conteúdos buscou "fugir", quais os conteúdos trabalhados, qual trabalho com a linguagem foi feito.

$\mathrm{Na}$ linha 3, destacamos que a aluna, talvez para se eximir da reponsabilidade como professora regente e do tipo de trabalho feito, insere um argumento de preservação da face que, nesse contexto, não pode ser sustentado. A aluna, por meio da conjunção concessiva (apesar de), argumenta que "apesar de sermos leigos", conseguiu atingir o objetivo da regência. Ora, a aluna, na época, estava no último ano do curso de Letras. Ao assumir-se como "leiga", é como se invalidasse todos os anos de estudos e de reflexão feitas até aquele momento. Ao fazer isso, acaba por invalidar o seu trabalho e o seu lugar como professor de português. Desde o lugar de "leigo", o professor pode fazer qualquer coisa e não pode ser responsabilizado por nada.

Se até aqui apresentamos duas posturas que prejudicam a construção de um lugar enunciativo pelo professor de português em formação, na sequência queremos mostrar um exemplo que indica como uma posição curiosa e corajosa pode quebrar o senso comum e o deslumbramento.

\section{A curiosidade e a coragem na formação do estagiário}

O estagiário instigado e implicado com o ato de pesquisar, a cada aula a que assiste ou registra, buscará insistentemente encontrar novas inquietações que o movam na construção de conhecimentos específicos da área de formação. Nesse sentido, a curiosidade é o combustível que alimenta a pesquisa e a produção de um professor em formação. Somente sendo muito curioso ele poderá, desprendendo-se das interpretações já prontas da realidade educacional, inventar formas diferentes de ensinar, de pensar certos fenômenos, de analisar os textos etc. É a partir de suas inquietações que poderá buscar respostas em diversas áreas do conhecimento, sondar as estantes das livrarias e bibliotecas, testar suas hipóteses em diferentes tipos de textos, conversar com diferentes profissionais. A exemplo das crianças, que são movidas pelo desejo da descoberta, o estagiário curioso sempre busca testar outros modos de promover o encontro tanto de si quanto do outro com o saber. Assim, não aceita como "natural" tudo observa ou ouve. 
Junto da curiosidade, a coragem sustenta o professor em formação no seu desejo de realizar um trabalho diferenciado. É preciso ter coragem para sustentar, frente ao outro, a singularidade e suportar a angústia de ser diferente ou, ainda, de pensar diferente, de questionar uma análise ou correção feita. Somente quem tem coragem não recua frente ao olhar externo e consegue sustentar seu desejo e buscar meios de mostrar as suas preocupações éticas, teóricas e metodológicas. Vejamos um exemplo.

01 O professor informou que queria que os alunos tivessem relacionado um fato maior, a epidemia do ebola, com uma informação menor, o texto da prova. Explicou, ainda, o que seria um primata. Portanto, os alunos deveriam ter o conhecimento sobre o contexto; deveriam já saber que a epidemia do ebola tem atingido seres humanos. Isso confundiu muitos alunos, que não conseguiram responder a questão correta. Porém, as alternativas realmente confundiam os alunos, na minha perspectiva tanto a alternativa

$07 \mathrm{~b}$ quanto a alternativa $\mathrm{c}$ estariam corretas.

De acordo com o texto, a epidemia de Ebola já matou mais de 300 gorilas, portanto, é

09 possível afirmar que a epidemia já matou 300 gorilas. Assim, a alternativa $\mathrm{b}$ está correta. $\mathrm{O}$ texto não diz a respeito de outros primatas, porém era possível associar o texto ao contexto. Portanto, o professor poderia considerar as

12 duas alternativas como corretas, mas não foi o que ocorreu.

$\mathrm{O}$ trecho foi retirado de um diário de campo de um aluno de uma universidade pública paulista. Relata uma aula de língua portuguesa em uma turma de Educação de Jovens e Adultos, na modalidade Ensino Médio. Na referida aula, o professor regente entrega provas corrigidas para os alunos e, oral e coletivamente, comenta cada questão da avaliação. O aluno-estagiário, por sua vez, não observa apaticamente essa atividade. Desde a linha 4, já demonstra uma atividade curiosa e atenta diante da correção. Ao invés de aceitar passivamente como correta 
a alternativa colocada pelo professor, o estagiário analisa o exercício, elenca o que o aluno deveria fazer para responder a questão de acordo com a perspectiva do professor e, ainda, discute os motivos pelos quais possivelmente vários alunos teriam escolhido como verdadeira outra resposta.

Temos aí um estagiário que está atento ao que acontece na sala de aula. Ele não tem medo de pensar diferentemente do professor regente. Tem um olhar curioso diante da aula e dos modos como os alunos se relacionam com o texto lido, com o tipo de resposta que deram etc. Constrói, portanto, um olhar de pesquisador ativo diante da aula que observa.

\section{Considerações finais}

Entendemos que a não construção de uma posição enunciativa desde a qual o professor de português em formação se paute tem consequências nefastas. Sem princípios claros daquilo que pensa a respeito da língua e objetivos definidos com relação ao lugar para onde quer levar o aluno, o professor em formação pode deixar-se reger por instrumentos normativos que pautarão seu modo de ensinar e seu olhar com relação à produção dos alunos, ao trabalho do professor regente e à aula de português.

Tais "instrumentos normativos", como, por exemplo, a gramática normativa; o livro didático; os documentos oficiais, os discursos do "politicamente correto" veiculados pelos meios de comunicação ou o senso comum impedem um olhar mais curioso e investigativo a respeito dos fenômenos da linguagem e do próprio ato de ensinar. Na contramão desse movimento, portanto, está uma posição enunciativa de alguém sempre curioso e motivado a encontrar novos modos de fazer a ponte entre o conhecimento acumulado e o seu aluno.

Assim, buscamos mostrar, neste texto, como podem se materializar na escrita, por um lado, impasses que indicam uma posição enunciativa mais passiva do professor em formação e, por outro, indícios de uma posição mais ativa e curiosa frente à sala de aula. Tais posições, a nosso ver, pode ter consequências para a formação de professores. Nesse aspecto, pensamos que é necessário que aquele que se dedica à formação de professores poderia problematizá-las nas aulas, mostrando, para os alunos, as consequências de assumir uma posição ou outra na prática pedagógica. 
Nesse sentido, tal como colocado por Fairchild (2008), o trabalho de escrita nos cursos de formação de professor não pode ser algo isolado ou avaliado somente no final do curso. Sendo um trabalho constante de reflexão ao longo do semestre, por exemplo, por meio da análise de fragmentos de diários ao longo das aulas, o professor formador poderá colaborar com o professor em formação ajudando-o a retroagir sobre seu escrito e, quem sabe, ajudá-lo, quando for o caso, a sair de uma posição enunciativa passiva para outra ativa. Para tanto, poderia ir reescrevendo com os alunos fragmentos dos diários, para que ficasse claro quais implicações um enunciado $\mathrm{X}$ e não $\mathrm{Y}$ teria na construção das interpretações que são feitas diante da realidade escolar.

Nosso intuito, com esse esforço de análise, é o de contribuir com a formação de professores cada vez mais implicados com a produção do conhecimento que se pode produzir ao longo das disciplinas de formação de professores e, por outro lado, mostrar que análise da escrita do que escrevem professores em formação é um campo muito profícuo para pesquisa e para a condução desse tipo de disciplinas.

\section{Referências}

Barzotto, V., Eufrásio, D. (2015). O relatório de estágio como manifestação do perfil profissional em Letras. Revista de Metodologia do Ensino de Língua Portuguesa. Número 3. Disponível em: $<$ http://www2.fe.usp.br/ lalec/revistamelp/numeros/numero03/ artigo_barzotto_eufrasio. htm>. 2008. Acesso em: 14 jun. 2015.

Barzotto, V., Puh, M. (2015). O perfil e a atitude investigativa do profissional de Letras diante do dado no relatório de estágio. In Riolfi, C. (Org.), Professor de português: como se forma, trabalha e entende sua prática (pp. 91-111). São Paulo: Paulistana.

Eufrásio, D. (2007) Traços das formações discursivas do dogma e da investigação em relatórios de pesquisa e de estágio: reflexão sobre o papel da pesquisa na formação docente (dissertação de mestrado). Faculdade de Educação da Universidade de São Paulo (FEUSP), São Paulo, SP, Brasil.

Fairchild, T. M. (2010) O professor no espelho. Refletindo sobre a leitura de um relatório de estágio na graduação em Letras. Revista Brasileira de Linguística Aplicada, 10 (1), 271-288.

(2009) Conhecimento técnico e atitude no ensino de língua portuguesa. Educação e Pesquisa, 35, 495-507. 
. (2008) Quatro considerações sobre a leitura de relatórios de estágio em Língua Portuguesa. In Krause-Lemke, C. e al. (Orgs.), Cultura, linguagem e educação: relações de poder (1 ${ }^{\mathrm{a}}$ ed, pp. 227-249). Guarapuava: UNICENTRO.

Larrosa, J. (1996) La experiencia de la lectura. Estudios sobre literatura y formación. Barcelona: Laertes S.A. de Editiones.

Pécora, A. (1992) Problemas de redação. São Paulo: Martins Fontes.

Pimenta, S. G. \& Lima, M. S. (2005/2006) Estágio e docência: diferentes concepções. Revista Poíesis. Vol3 (n. 3 e 4), 5-24.

Riolfi, C. (2003) Ensinar a escrever: considerações sobre a especificidade do trabalho da escrita. Leitura. Teoria \& Prática. Revista da Associação de Leitura do Brasil, 40, 47-51.

Riolfi, C., Andrade, E., Rocha, A. R. (2006). O sujeito e o trabalho da escrita: perseguindo os meandros do ato de escrever. In Rezende, N. L., Riolfi, C., Semeghini-Siqueira, I. (Orgs.). Linguagem e educação: implicações técnicas, éticas e estéticas (pp. 35-72). São Paulo: Humanitas.

Zabalza, M. (2004) Diarios de clase. Un instrumento de investigación $y$ desarrollo profesional. España: Narcea. 